\title{
Benchscale Evaluation of Nanodiamond Oil Additives
}

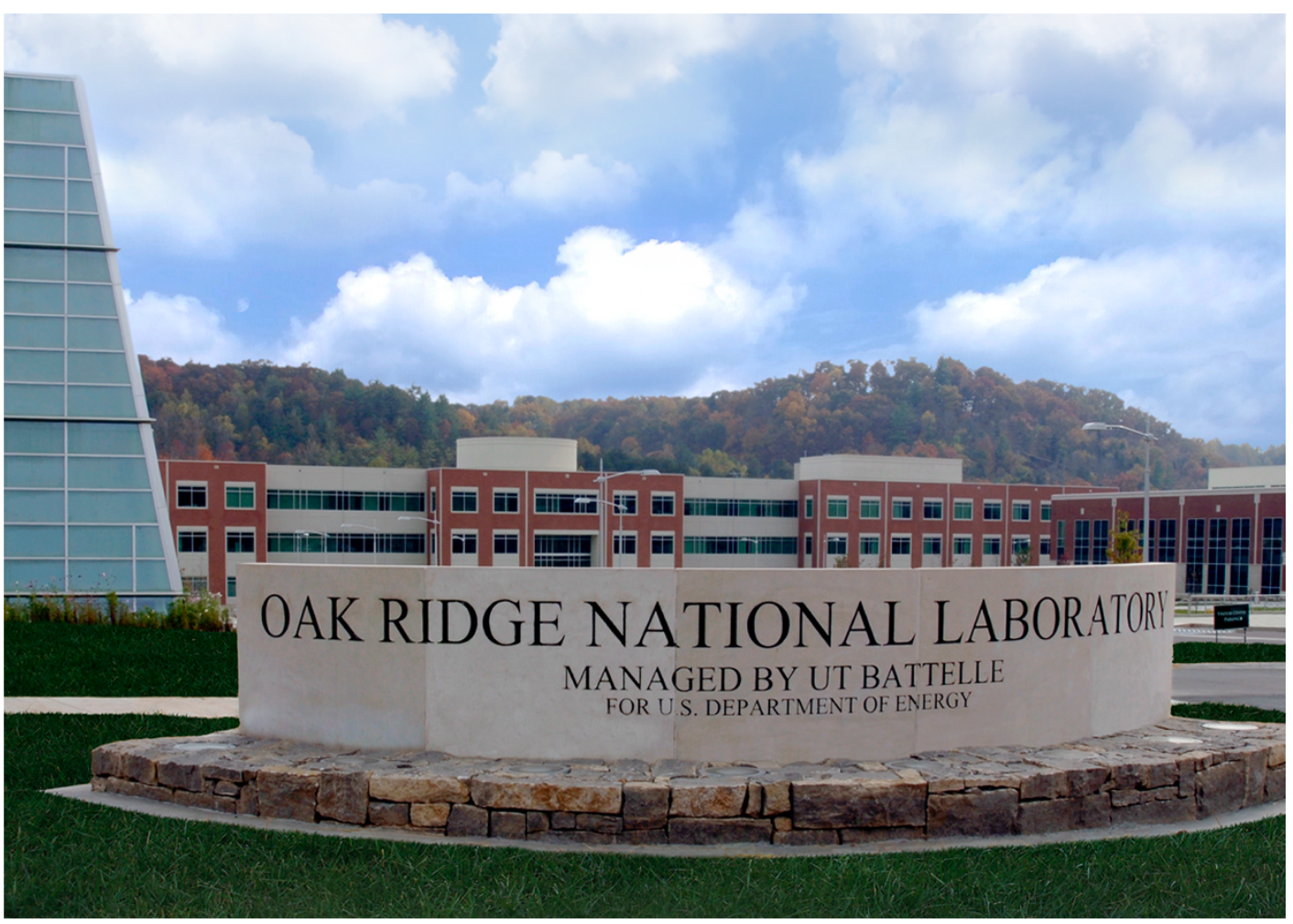

Jun Qu

Austin Shaw

Sladjan Lazarevic

Brian West

David Leith

May 2018 


\section{DOCUMENT AVAILABILITY}

Reports produced after January 1, 1996, are generally available free via US Department of Energy (DOE) SciTech Connect.

Website http://www.osti.gov/scitech/

Reports produced before January 1, 1996, may be purchased by members of the public from the following source:

National Technical Information Service

5285 Port Royal Road

Springfield, VA 22161

Telephone 703-605-6000 (1-800-553-6847)

TDD 703-487-4639

Fax 703-605-6900

E-mail info@ntis.gov

Website http://www.ntis.gov/help/ordermethods.aspx

Reports are available to DOE employees, DOE contractors, Energy Technology Data Exchange representatives, and International Nuclear Information System representatives from the following source:

Office of Scientific and Technical Information

PO Box 62

Oak Ridge, TN 37831

Telephone 865-576-8401

Fax 865-576-5728

E-mail reports@osti.gov

Website http://www.osti.gov/contact.html

This report was prepared as an account of work sponsored by an agency of the United States Government. Neither the United States Government nor any agency thereof, nor any of their employees, makes any warranty, express or implied, or assumes any legal liability or responsibility for the accuracy, completeness, or usefulness of any information, apparatus, product, or process disclosed, or represents that its use would not infringe privately owned rights. Reference herein to any specific commercial product, process, or service by trade name, trademark, manufacturer, or otherwise, does not necessarily constitute or imply its endorsement, recommendation, or favoring by the United States Government or any agency thereof. The views and opinions of authors expressed herein do not necessarily state or reflect those of the United States Government or any agency thereof. 
ORNL/TM-2018/836

CRADA/NFE-16-06139

\title{
Benchscale Evaluation of Nanodiamond Oil Additives
}

\author{
Jun Qu, Austin Shaw, Sladjan Lazarevic \\ Materials Science and Technology Division \\ Brian West \\ Energy \& Transportation Science Division
}

David Leith

Cool-X LLC

Date Published: May 2018

\author{
Prepared by \\ OAK RIDGE NATIONAL LABORATORY \\ Oak Ridge, Tennessee 37831-6283 \\ managed by \\ UT-BATTELLE, LLC \\ for the \\ US DEPARTMENT OF ENERGY \\ under contract DE-AC05-00OR22725
}

Approved for Public Release 


\begin{abstract}
This CRADA between Cool-X and ORNL was to investigate the impact of diamond nanoparticles as diesel engine oil additives on lubricating behavior and gain fundamental understanding of the friction and wear reduction mechanisms. Systematic tribological bench tests were used for evaluating the Cool-X diamond nanoparticles (ND) as candidate diesel engine oil additives, and surface characterization was carried out to reveal the friction reduction mechanisms. No significant micro-rolling effect or increased oil pressure-viscosity coefficient was observed. Instead, a faster running-in and moderate friction reduction were achieved by the ND in tests of used diesel engine components, which was attributed to the polishing effect. ND agglomeration seemed to a problem and could significantly impair the functionality and future research is needed to seek the mitigation.
\end{abstract}

\title{
Statement of Objectives
}

To investigate the impact of diamond nanoparticles as diesel engine oil additives on lubricating behavior and gain fundamental understanding of the friction and wear reduction mechanisms.

\section{Benefits to the Funding DOE Office's Mission}

This project was sponsored by the DOE EERE Vehicle Technologies Office (VTO). The work scope of this project is to develop diamond nanoparticles as novel lubricant additives to potentially improve the automotive engine efficiency and durability, which is well in line with the VTO's mission to develop more energy efficient and environmentally friendly transportation technologies. 


\section{Technical Discussion of Work Performed by All Parties}

\section{Background}

The purpose of this Cooperative Research and Development Agreement (CRADA) between UT-Battelle, LLC ("Contractor") and Cool X, LLC ("Participant") is to investigate the impact of diamond nanoparticles (NPs) as diesel engine oil additives on lubricating behavior and gain fundamental understanding of the friction and wear reduction mechanisms.

Currently, it is unknown how nanoparticles change the topography of friction surfaces and the effect on lubrication. The oil additive industry faces three challenges: difficulty in conducting tests to measure fuel economy impact, consumer's skepticism of oil additive technologies and limited product knowledge, and the costs associated with the American Petroleum Institute (API) certification.

Using NPs as lubricant additives to reduce friction and/or wear has been reported in recent literature. In this project, the feasibility and mechanism of using diamond nano NPs as diesel engine oil additives were investigated.

\section{Experimental and materials}

The interface of diesel engine piston top ring against cylinder liner was identified as the main tribological interface to evaluate with the nano-diamond additive. The Participant provided diesel engine piston top rings and cylinder liners in both new and used (but still working) conditions. The Participant also provided four lubricants for tribological evaluation at ORNL: (1) commercial CJ-4 SAE 15W-40 diesel engine oil, (2) SAE 15W-40 diesel engine oil additized with Cool-X nano-diamond (ND) additive, (3) a PC-11 SAE 10W-30 diesel engine oil, and (4) a PC-11 SAE 10W-30 diesel engine oil with ND additive.

Tribological tests were conducted to evaluate the candidate lubricants in boundary, mixed, and elastohydrodynamic lubrication regimes, all being experienced as at the ring-on-liner interface in an actual engine. Three test configurations were used for evaluating the ND as diesel engine oil additives under various conditions:

- Cylinder-on-flat Stribeck curve tests to study the effects of ND on friction in mixed and elastohydrodynamic lubrication regimes. A Stribeck curve was generated for each candidate lubricant using cylinder-on-flat configuration on a variable load-speed journal bearing tester (VLBT, see Fig. 1). The load was $100 \mathrm{~N}$ and the sliding velocity was in the range of $0.2-1.5 \mathrm{~m} / \mathrm{s}$.

- Ball-on-flat reciprocating sliding boundary lubrication test (similar to ASTM G 133) using a Plint TE-77 tribometer, as shown in Fig. 2a, to study the effects of ND on boundary friction and wear at an extreme Hertzian contact pressure (up to $20 \mathrm{X}$ compared to that in an engine). In each test, an AISI 52100 bearing steel ball in $10 \mathrm{~mm}$ diameter was used to slide against a GL35 grey cast iron flat. The ball-on-flat tests were executed at $10 \mathrm{~Hz}$ oscillation frequency with $10 \mathrm{~mm}$ stroke (average speed: $0.2 \mathrm{~m} / \mathrm{s}$ ), under a 100, 50, and $25 \mathrm{~N}$ load for 1,10 , and $20 \mathrm{~km}$ of sliding, respectively. Tests at $100 \mathrm{~N}$ load and $1 \mathrm{~km}$ sliding was at both room temperature and $100{ }^{\circ} \mathrm{C}$ and the rest were done at $100{ }^{\circ} \mathrm{C}$.

- A unique ring-on-liner (see Fig. 2b) reciprocating sliding boundary lubrication test using the Plint TE-77 tribometer to study the effects of ND on boundary friction and wear at moderate contact pressure (similar to that in an engine). ORNL machined the actual diesel piston rings and liners from Cool-X into test coupons for the tests. The ring-on-liner tests were carried out under a load of $240 \mathrm{~N}$ (44 MPa mean contact pressure, equivalent to $4.7 \mathrm{MPa}$ in-cylinder pressure), at a $10 \mathrm{~Hz}$ oscillation frequency with a $10 \mathrm{~mm}$ stroke, and at an oil temperature of $100{ }^{\circ} \mathrm{C}$ for a sliding distance of 20-70 km. 
In any case, fhe friction coefficient was monitored in-situ and the wear volume was quantified using a white light interferometer (Wyko NT9100).

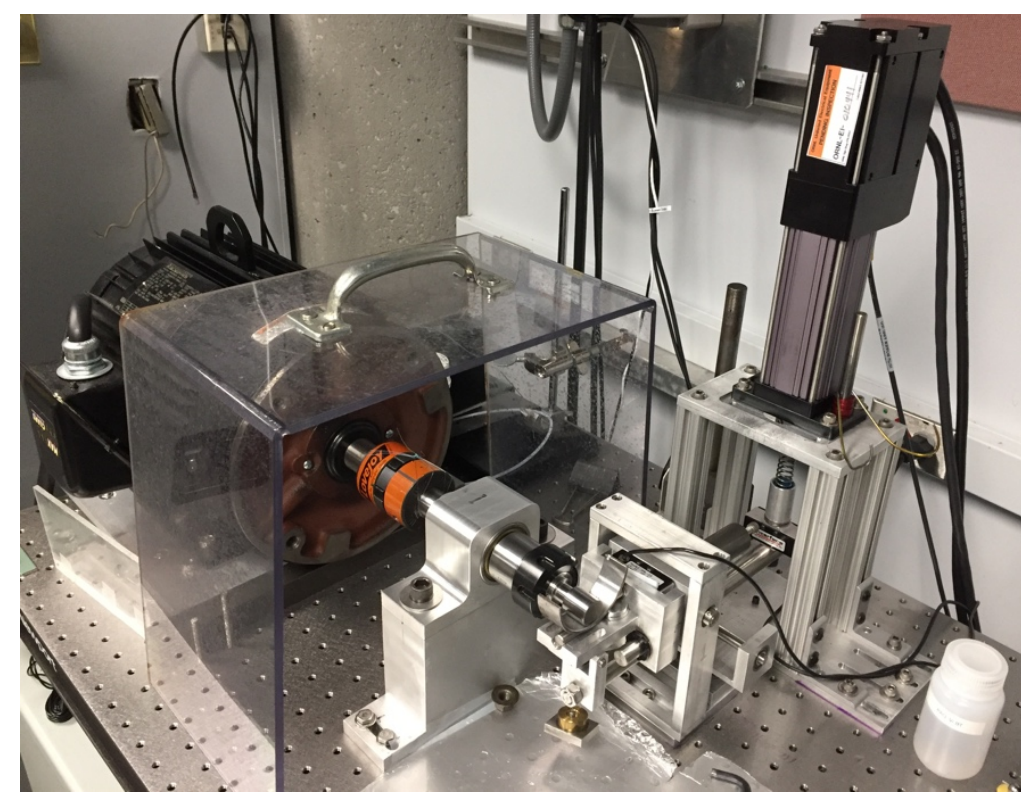

Figure 1. Variable load-speed journal bearing tester (VLBT) for generating Stribeck curves (friction behavior in boundary, mixed, and elastohydrodynamic lubrication).
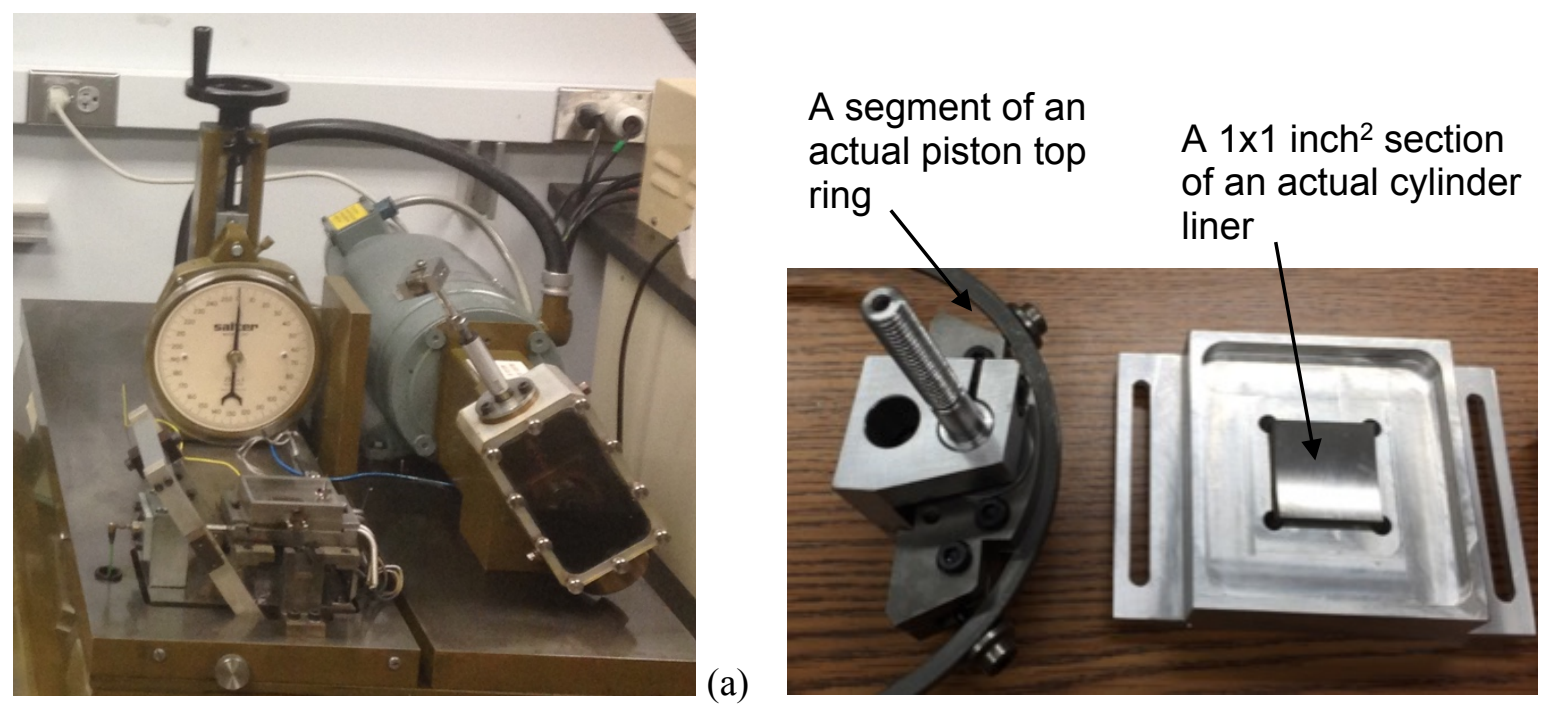

(b)

Figure 2. Plint TE-77 tribometer (a) and the ring-on-liner test configuration (b) for evaluating boundary lubrication friction and wear.

Surface roughness was measured before and after the wear testing using a surface profiler. Scanning electron microscopy (SEM) and energy dispersive spectroscopy (EDS) were used to examine the worn 
surface morphology and composition to provide mechanistic insights for the interactions between the nano-diamond additives and the contact surface.

The Participant proposed to conduct a fleet test using a substantial number of vehicles with tracking of the oil temperature and condition over time in attempt to correlate the impact of diamond nano-NPs with the fuel economy.

\section{Results and Discussion}

There are various hypotheses for how the ND functions at a tribological interface including (i) acting like nano-scale ball bearings, (ii) blocking oil flow to increase the oil pressure-viscosity coefficient (VPC), and (iii) surface polishing. The polishing effects were examined by measuring the surface roughness before and after the tribotests. An increase in VPC would notably reduce friction in mixed lubrication but slightly increase the friction in elastohydrodynamic (EHD) lubrication. Significant nano-scale ball bearing effect was not expected because the diamond particles are so much harder than the cast iron engine cylinder liner and would be penetrating into the iron surface under high contact pressure rather than rolling on it.

Figure 3 compares the cylinder-on-flat sliding test-generated Stribeck curves of the PC-11 SAE 10W-30 diesel engine oil without and with the ND, which suggest little effect of the ND on the friction behavior in either the mixed or the EHD lubrication regime. Results did not support the literature hypotheses of (i) nano-scale ball bearings (otherwise would reduce mixed lubrication friction) or (ii) blocking oil flow to increase the oil pressure-viscosity coefficient (otherwise would reduce mixed lubrication friction and increase EHD lubrication friction).

Diamond nano NPs were also proposed in the literature to provide a surface polishing effect under boundary lubrication. To verify this, we first conducted a series of ball-on-flat reciprocating sliding boundary lubrication tests under an extreme Hertzian contact pressure for the PC-11 SAE 10W-30 diesel engine oil without and with the ND. The ND had insignificant impact on the friction and wear results in the high-load $(100 \mathrm{~N})$, short-duration $(1 \mathrm{~km})$ tests, as shown in Fig. 4. However, the elongated test (10 $\mathrm{km}$ ) at a lower load $(50 \mathrm{~N})$ showed $>20 \%$ reduction in steady-state friction after a high-friction running-in process, as shown in Fig. 5. Further reduction in load $(25 \mathrm{~N})$ and extension in sliding $(20 \mathrm{~km})$ suggested a potential of up to $50 \%$ friction reduction (see Fig. 6). Such a friction reduction may not be attributed to the proposed polishing effect because similar roughness was observed on the worn surface lubricated by the oil with and without the ND ( $R_{\mathrm{a}}: 2.56$ vs. $2.58 \mu \mathrm{m}$ at $50 \mathrm{~N}$ and $1.17 \mathrm{vs.} 1.37 \mu \mathrm{m}$ at $\left.25 \mathrm{~N}\right)$ though $R_{\mathrm{a}}$ alone does not represent all the roughness features. Alternatively, it could be a result of reduced adhesion with ND as a third-party material between the two contact surfaces. 


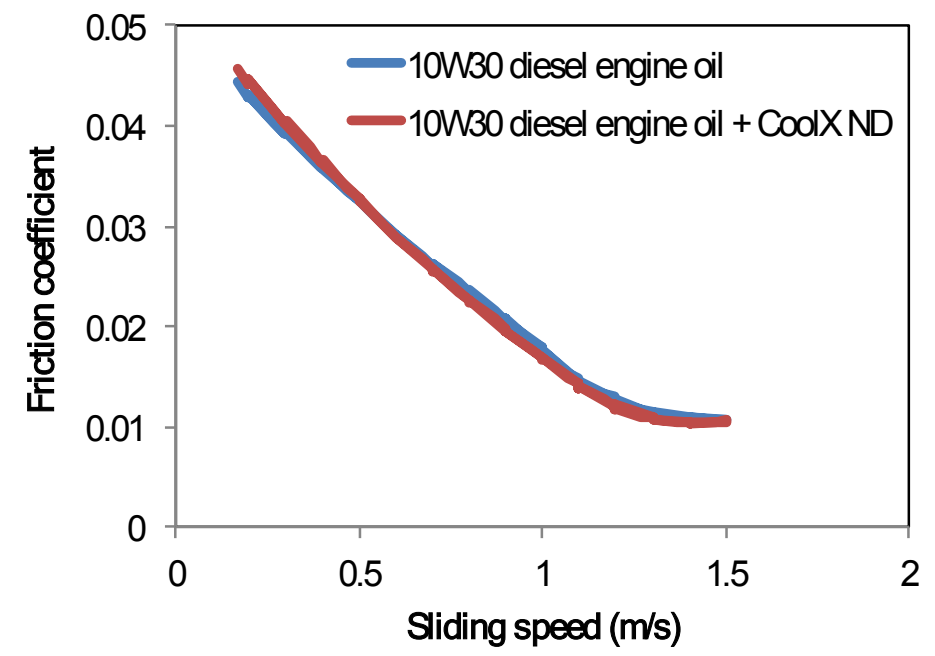

Figure 3. Stribeck curves showing little effect of the diamond nano NPs on the friction behavior in mixed or EHD lubrication.
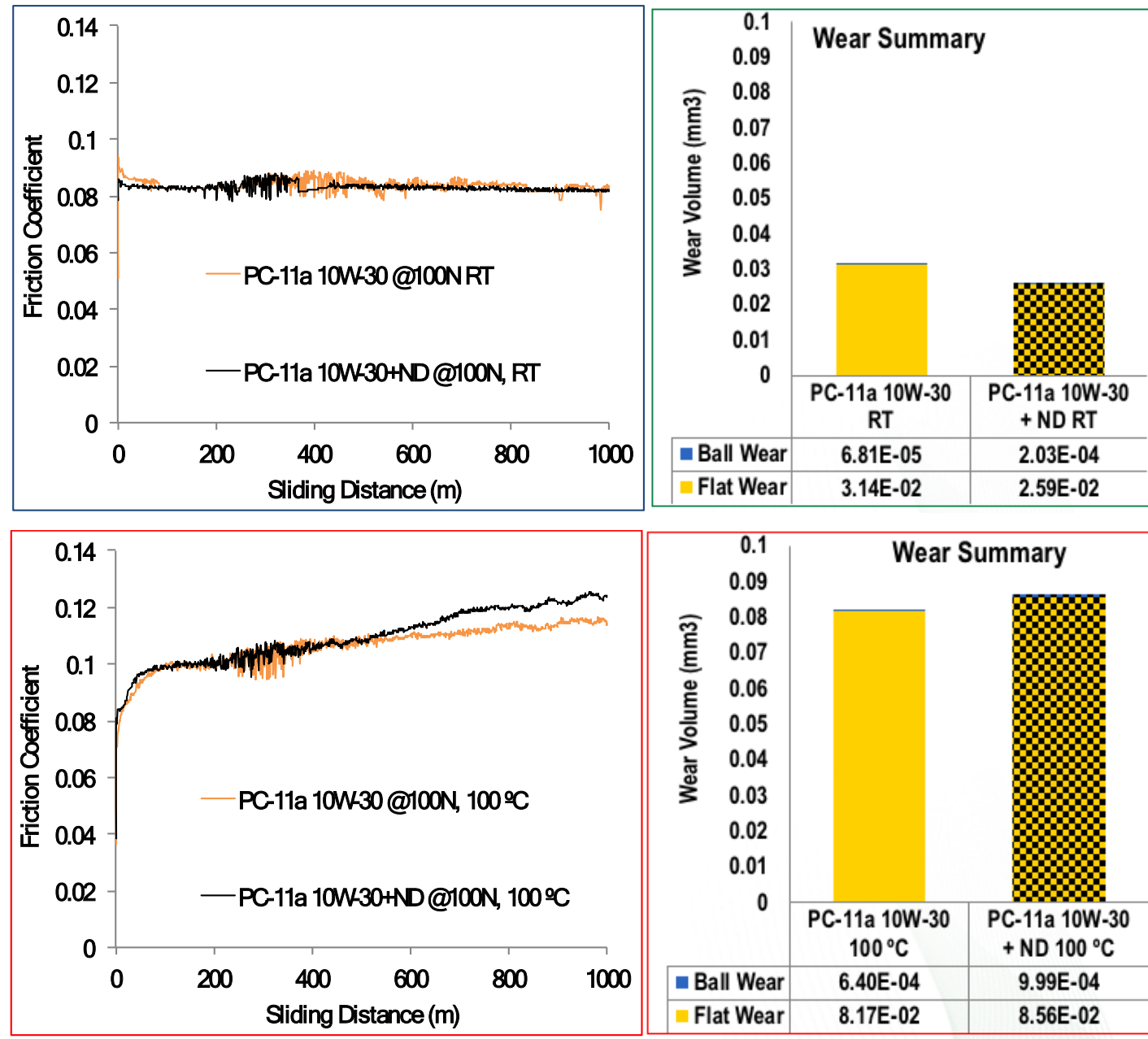

Figure 4. High-load $(100 \mathrm{~N})$, short-duration $(1 \mathrm{~km})$ ball-on-flat boundary lubrication tests at room temperature and $100{ }^{\circ} \mathrm{C}$ showing insignificant effect of $\mathrm{ND}$ on the friction and wear behavior. 


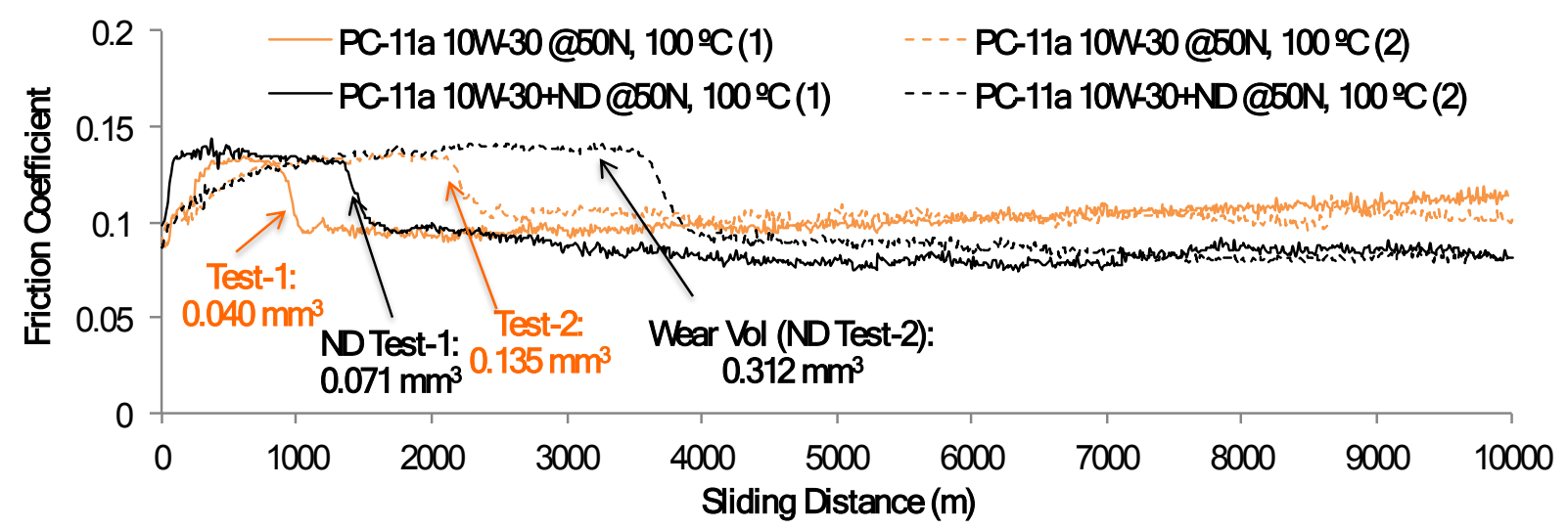

Figure 5. Medium-load $(50 \mathrm{~N})$, medium-duration $(10 \mathrm{~km})$ ball-on-flat boundary lubrication tests at $100{ }^{\circ} \mathrm{C}$ showing $20 \%$ reduction in steady-state friction by ND.

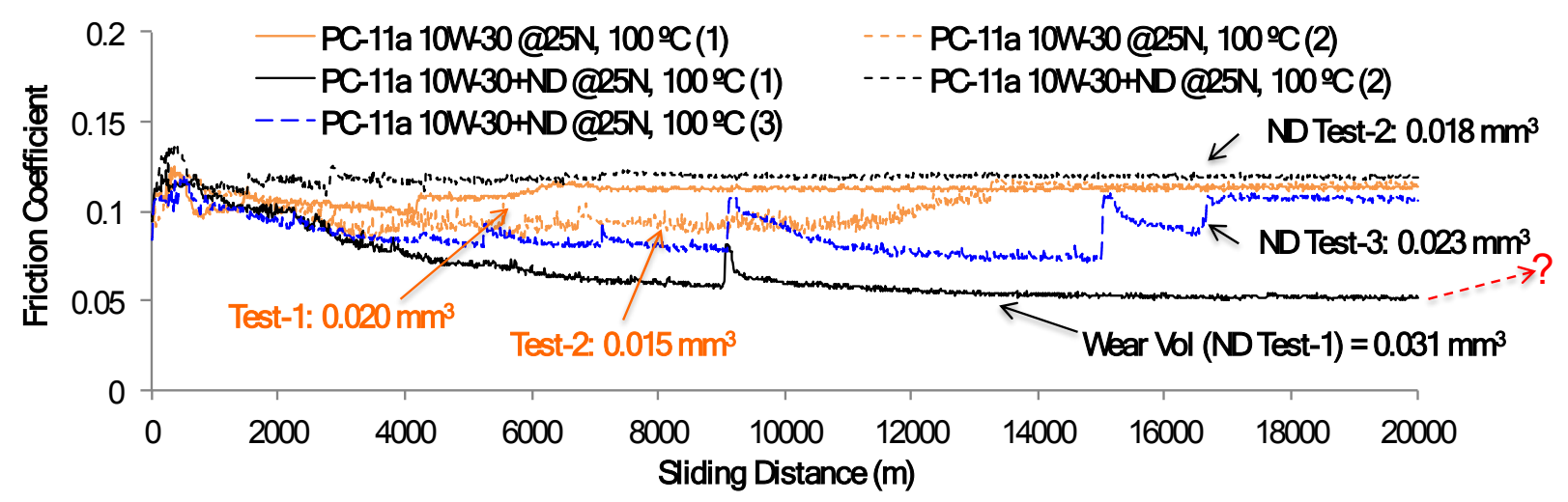

Figure 6. Low-load $(25 \mathrm{~N})$, long-duration $(20 \mathrm{~km})$ ball-on-flat boundary lubrication tests at $100{ }^{\circ} \mathrm{C}$ showing up to $50 \%$ reduction in steady-state friction by ND.

Ring-on-liner reciprocating sliding boundary lubrication tests were then conducted to study the effects of $\mathrm{ND}$ on the friction and wear at a moderate contact pressure (similar to that in an engine). Test specimens were machined off both new and used diesel engine piston rings and cylinder liners. The ND was introduced to two diesel engine oils, CJ-4 SAE 15W-40 and PC-11 SAE 10W-30. However, results did not show much friction reduction by the introduction of ND, even running for up to $70 \mathrm{~km}$ (see Fig. 7).

The team then thought that the polishing effect could possibly be more pronounced on used engine parts whose surfaces inevitably have deposits as a result of burned oil and fuel upon combustion. A set of used piston rings and cylinder liner from a disassembled diesel engine were later provided by Cool-X, as shown in Fig. 8. Combustion-induced deposits appeared on both the ring and liner surfaces, and the addition of ND into the engine oil was expected to help on the deposit removal. 


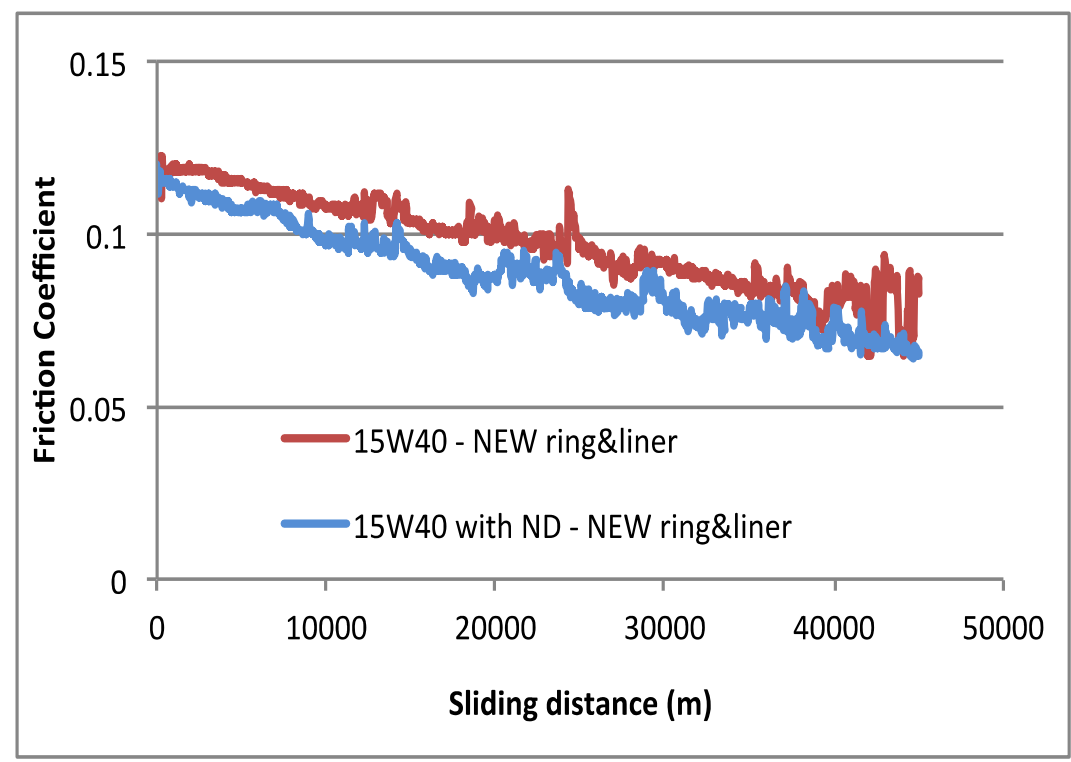

(a) CJ-4 SAE 15W-40 diesel engine oil without and with ND

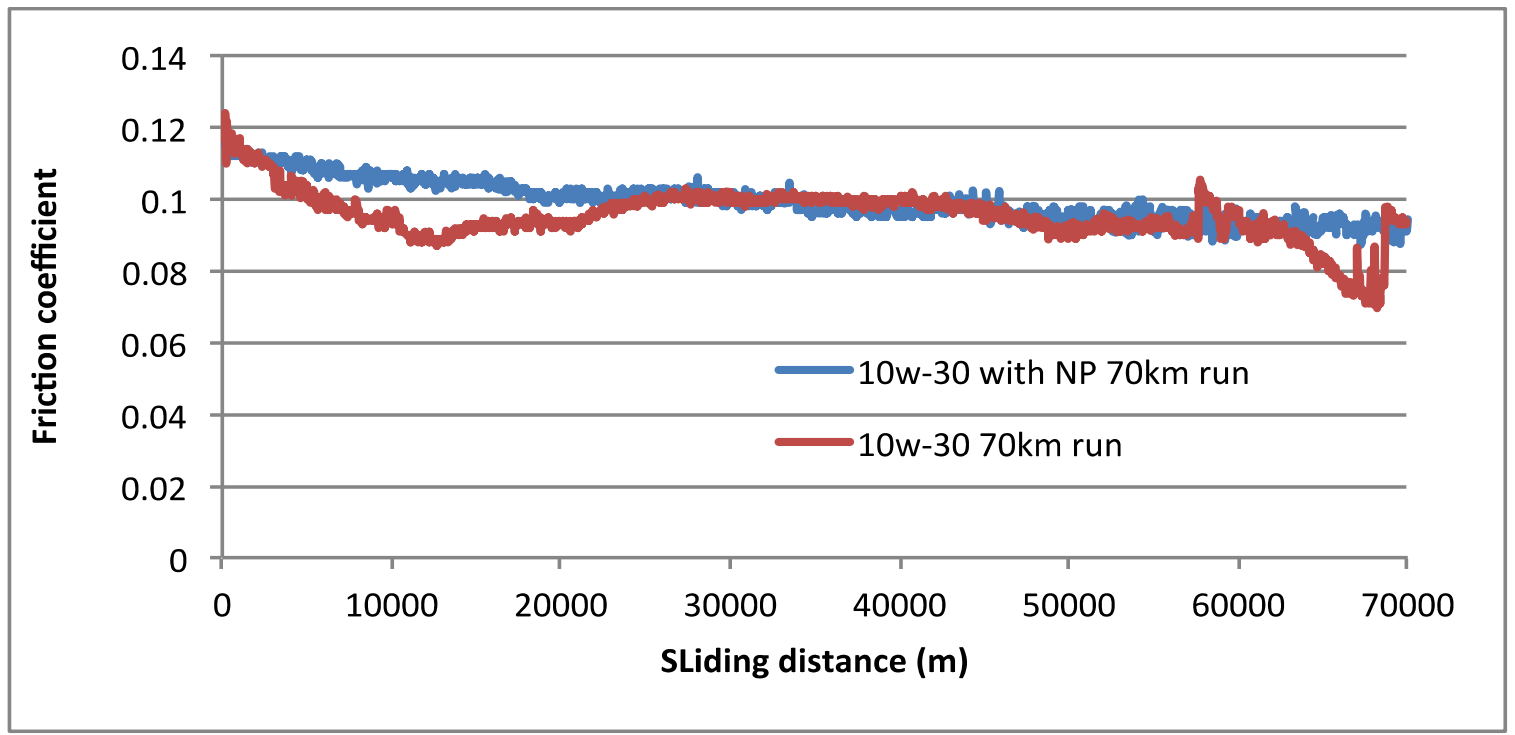

(b) PC-11 SAE 10W-30 diesel engine oil without and with ND

Figure 7. Friction traces of new ring-liner pairs tested in diesel engine oils without and with ND, showing insignificant impact of ND on friction. 


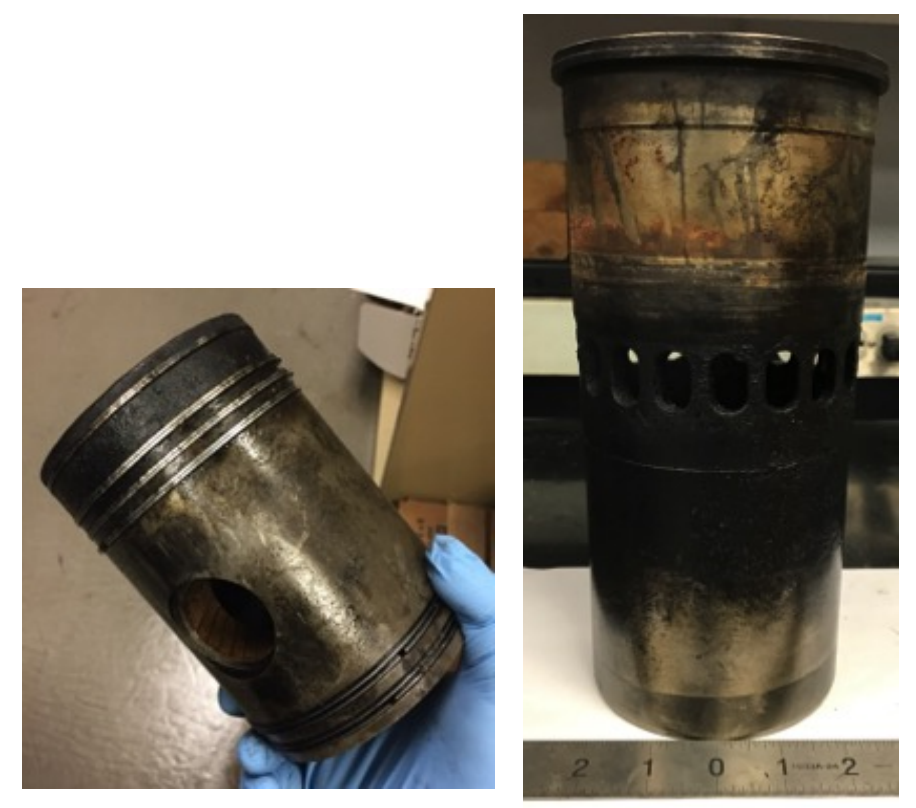

Figure 8. Used diesel engine piston with rings (left) and cylinder liner (right) showing deposits on the surface.

Ring-on-liner reciprocating sliding boundary lubrication tests of $45 \mathrm{~km}$ (62.5 hours) were conducted on the diesel engine oils without and with ND using the specimens cut off the used piston top ring and matching cylinder liner. Initial tests however did not exhibit any benefit from the ND, as shown in Fig. 9. The ineffectiveness of ND was possibly caused by particle agglomeration. Based on the information provided by Cool-X, the nominal individual ND particle size is $8-10 \mathrm{~nm}$ and the agglomerates in the oil are about $50 \mathrm{~nm}$. Since the oil sample has been sitting on the shelf for more than 6 months, it is possible that the agglomeration had deteriorated. We suspected that the agglomerates had grown too large to get into the contact interface and thus cannot make much influence on the friction behavior. To address this issue, sonication ( $30 \mathrm{~min}$ ) was then used to break down the ND agglomerates in the oil before the tribotesting and repeat the $45 \mathrm{~km}$ tests. Results are also compared in Fig. 9. For the 15W-40 engine oil, 30-min sonication of the ND oil prior to the test generated a quick friction reduction in the beginning of the test. The 10W-30 engine oil without ND or sonication gradually reduced the friction coefficient over the entire course of the 62.5 hours testing time to reach 0.106 at the end. Sonication actually made the $10 \mathrm{~W}-30$ engine oil without ND perform worse with a higher stead-state friction of 0.116 and higher fluctuations. In contrast, sonication substantially improved the frictional behavior of the ND-additized oil, which reduced the friction coefficient and reached a steady-state around 0.106 after 10 hours testing. The surface deposit on the used ring and liner appeared to be removed more effectively after the $45 \mathrm{~km}$ testing in the ND-additized oil, as shown in Fig. 10.

While the tested ring surfaces appeared to have similar roughness, the worn liner surfaces tested in the sonicated ND-containing oils were consistently smoother than those tested in the oils w/o ND, as compared in Table 1. The removal of deposit is believed to be responsible for the surface smoothening and friction reduction, and the sonication seemed to effectively break down the ND agglomerates to allow the particles getting into the contact interface to help polish off the deposit more quickly. 

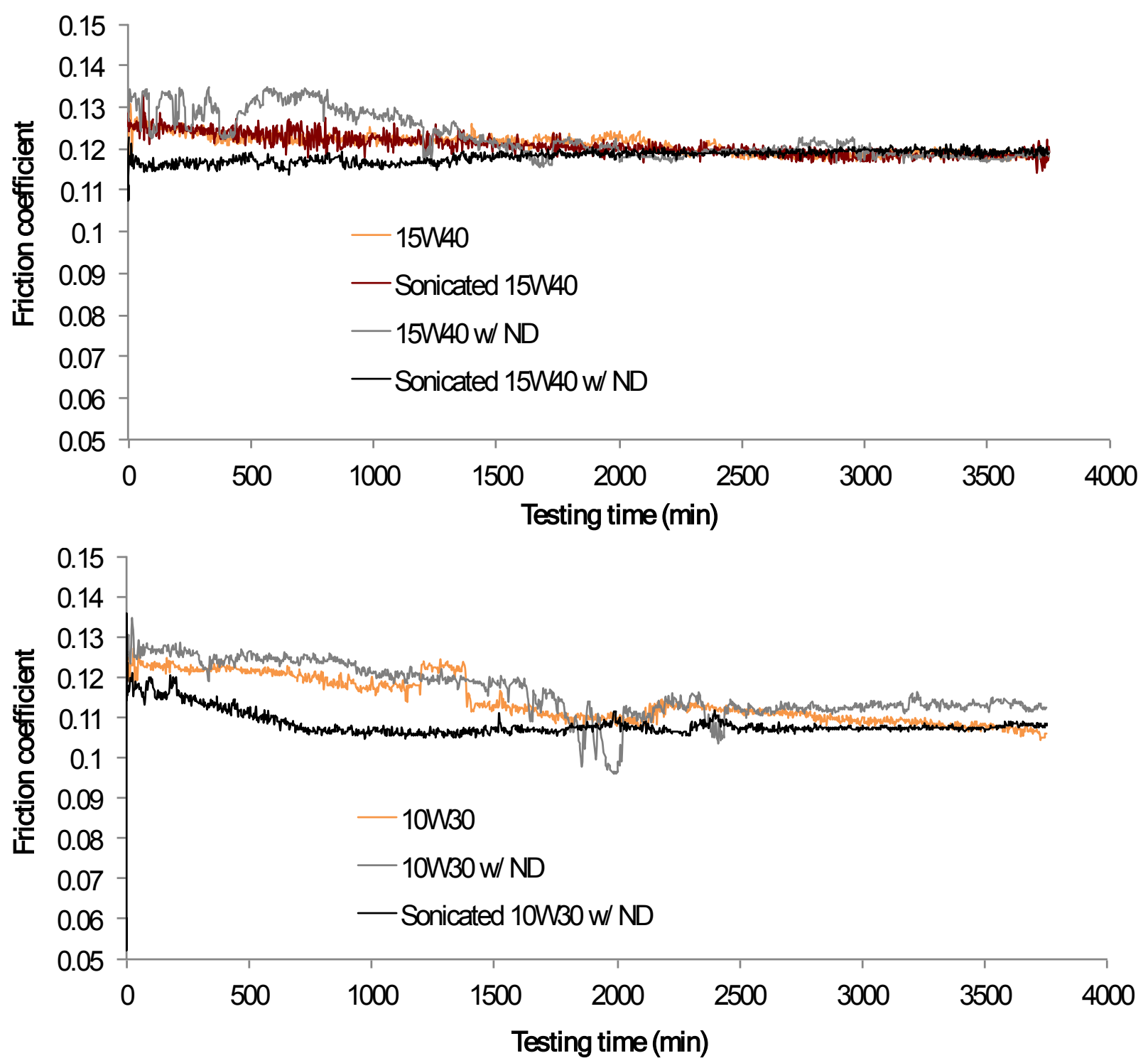

Figure 9. Friction traces of $45 \mathrm{~km}$ boundary lubrication tests of diesel engine oils without and with ND using used piston ring and cylinder liner. The sonicated ND-containing engine oil showed a faster friction reduction possibly due to more effective deposit removal. 


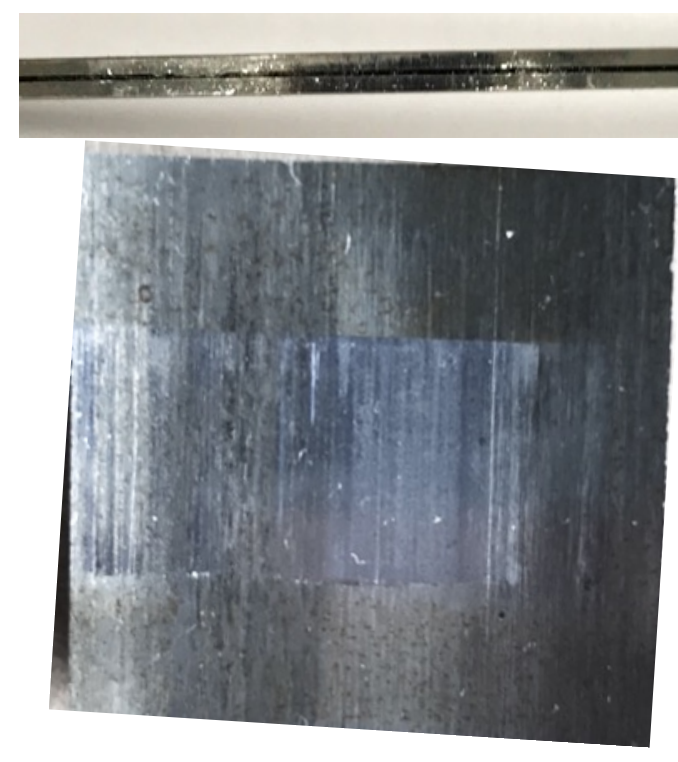

(a)
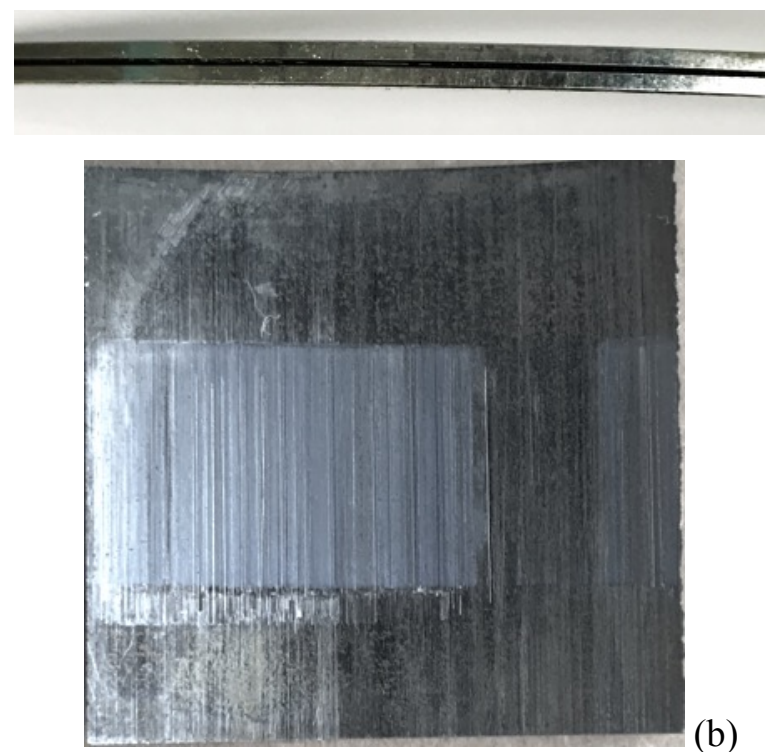

Figure 10. Used piston ring and cylinder liner samples after the $45 \mathrm{~km}$ boundary lubrication tests in SAE 10W-30 diesel engine oils without (a) and with (b) ND particles. Surface deposit appeared to be removed more effectively by the ND-additized oil.

Table 1. Comparison of surface roughness of piston ring and cylinder liner specimens as received and tested in diesel oils without and with ND.

\begin{tabular}{lccccc}
\hline $\begin{array}{l}\text { Roughness } \\
(\mu \mathrm{m})\end{array}$ & $\begin{array}{c}\text { As- } \\
\text { received }\end{array}$ & $\begin{array}{c}\text { Tested by 15W- } \\
40 \mathrm{w} / \mathrm{o} \mathrm{ND}\end{array}$ & $\begin{array}{c}\text { Tested by 15W- } \\
40 \mathrm{w} / \mathrm{ND}\end{array}$ & $\begin{array}{c}\text { Tested by 10W- } \\
30 \mathrm{w} / \mathrm{o} \mathrm{ND}\end{array}$ & $\begin{array}{c}\text { Tested by 10W- } \\
30 \mathrm{w} / \mathrm{ND}\end{array}$ \\
\hline Ring $\left(R_{\mathrm{q}}\right)$ & 0.16 & 0.14 & 0.15 & 0.15 & 0.18 \\
\hline Liner $\left(R_{\mathrm{a}}\right)$ & 0.29 & 0.39 & 0.29 & 0.32 & 0.11 \\
\hline
\end{tabular}

\section{Challenges}

Diamond nanoparticles in the engine oil are suspected to agglomerate over time to grow too big to get into the contact interface, resulting in loss of functionality. The trend to use PAOs and other synthetic lubricants with ever lower viscosity could make this an even greater challenge. Mitigation: Sonication can temporarily improve the ND dispersion but a more effective surfactant is needed to for long term stability.

In general, ever improving lubricant additive technology is using zero weight or lower viscosity oils with enhanced additive packages to reduce engine friction. As engine technology and lubricants improve, the economic benefits of marginal improvements due to lubricant additives become harder and harder to measure and quantify. The Participant (Cool X) abandoned its proposed fleet trial in large part because the size of the planned trial would not be sufficient to detect the marginal changes in friction, given the variability and precision of the available measurements. Cool X wanted to use OBDII devices to datalog fuel consumption, for example, but found that the devices acquired lacked the capability to capture the data at a fast enough rate to track the instantaneous fuel consumption with the desired precision.

\section{Subject Inventions (As defined in the CRADA)}


None.

\section{Commercialization Possibilities}

At present, Cool $\mathrm{X}$ judges the prospects for commercialization as remote.

The market for additives is competitive and almost entirely B2B; consumers lack the technical knowledge to evaluate oils in general, let alone additives, and remain skeptical of "snake oil" claims. To break through, an additive must be both superior and cost efficient. Our nanodiamond materials cost more than other existing additive packages. ND manufacturing might benefit from economies of scales with broad adoption or new uses; at present there is little sign of that occurring.

The benefits of additives are mostly measured in fuel saved or reduction in wear / enhanced service life. With oil prices at roughly $\$ 45$ per barrel in last a few years, and with little prospect for much higher prices in the future with the shale oil boom, customers have been less focused on new fuel savings technologies, particularly with the prospect of potential reductions in CAFE standards. As time goes on, market trends are unfavorable. Average fleet fuel economy is increasing, as more efficient new cars replace older, less fuel-efficient clunkers. Truck fleets are updated much more quickly than passenger vehicles; for the marginal benefit of new, expensive additives will decline over time.

The bench test results at ORNL were less encouraging than hoped. While the hypothesized reduction in surface roughness through polishing was indeed established, and wear was reduced, it did not seem to yield significant reductions in friction, particularly in next generation PC-11 type oils. While ball-on-flat testing did suggest that up to $50 \%$ reductions in friction could be achieved over time at low loads $(25 \mathrm{~N})$, at higher loads said to equate to engine conditions ( $240 \mathrm{~N}$ is thought to be equivalent to $4.7 \mathrm{MPa}$ incylinder pressure in the ORNL ring-on-liner tests) there was little difference noted.

In any case, the polishing effect also seemed to create variable results - which was reflected in Cool-X testing in cars and trucks before and during the project. Some vehicles showed measurable, even dramatic reductions in friction, while many showed no difference at all. It is a challenge to market an additive without repeatable consistent output.

The team also suggested that perhaps the reduction in friction might be due in part to reduced adhesion (diamonds are inert) because changes in $R_{\mathrm{a}}$ did not correlate with changes in measured friction. Cool-X thinks in a three-body lubrication system $R_{\mathrm{a}}$ may not be the best measure to predict changes in friction. More work is needed.

The Participant has changed the focus of its research efforts to investigating the reduction in sump oil temperatures achieved by adding ND. Prior and ongoing testing suggests that reduction of $5-15{ }^{\circ} \mathrm{C}$ is attainable for engines or gearboxes operating at peak loads. Oils are particularly sensitive to breakdown at high temperatures; a $10^{\circ} \mathrm{C}$ increase in oil temperature can reduce oil life by half. The highly thermally conductive ND appeared to be effective in transferring heat from the sump to the block or oil pan, reducing sump oil temperatures. Cool $\mathrm{X}$ has ongoing testing in a gear oil subject to extreme thermal stresses; it is also investigating a trial this summer in extreme weather conditions (think Phoenix in the summertime).

For these applications, the Project has advanced the prospects of commercialization. At the very least, it has demonstrated that the ND do not cause excess wear, nor increased friction. So if other benefits prove very beneficial (such as enhanced oil life) there may be a market yet. 
There remains the technical challenge of ND agglomeration and dispersion remained to be fully mitigated. In Cool X's assessment, this may not be a major issue, but it will vary depending on the base oil and additive packages.

\section{Plans for Future Collaboration}

Unknown because the Participant had stopped communications.

\section{Conclusions}

All ORNL tasks have been successfully completed with all ORNL-responsible milestones (1, 2, and 3a) met. Systematic tribological bench tests were used for evaluating the Cool-X diamond nanoparticles (ND) as candidate diesel engine oil additives, and surface characterization was carried out to reveal the friction reduction mechanisms. Stribeck curve tests did not observe reduction in mixed and elastohydrodynamic friction by ND, suggesting little micro-rolling effect or increased oil pressure-viscosity coefficient, as hypothesized in the literature. Boundary lubrication tests at a moderate contact pressure (similar to that in an engine) of used ring-on-liner showed faster running-in and deposit removal by ND resulting in a slightly lower friction. Worn surfaces lubricated by the ND-containing oils were smoother than those by the oils w/o ND, confirming the proposed polishing effect. ND agglomeration seemed to a problem and could significantly impair the polishing functionality and future research is needed to seek the mitigation.

\section{Acknowledgements}

The authors thank R.J. Parten and K. Cooley from ORNL for sample preparation. Research was sponsored by the Vehicle Technologies Office, Office of Energy Efficiency and Renewable Energy, U.S. Department of Energy. A. Shaw and S. Lazarevic were supported via the DOE Advanced Short-Term Research Opportunity (ASTRO) program. 